\title{
Development and implementation of ecological and economical flood protection measures at an alpine river
}

\author{
Ursula Stephan ${ }^{1, *}$, Silke Kainz ${ }^{1}$, Michael Hengl ${ }^{1}$, Alexander Bickel ${ }^{2}$, Markus Mähr ${ }^{2}$ \\ and Wolfgang Burtscher ${ }^{3}$ \\ ${ }^{1}$ Institute for Hydraulic Engineering and Calibration of Hydrometrical Current-Meters, Federal \\ Agency for Water Management, Severingasse 7, 1090 Vienna, Austria \\ ${ }^{2}$ Breuß Mähr Bauingenieure $\mathrm{GmbH}$, Ingenieurbüro für Kulturtechnik u. Wasserwirtschaft, \\ Straßenbau, Flussbau und Wasserkraftanlagen, Werben 19, 6842 Koblach, Austria \\ ${ }^{3}$ Amt der Vorarlberger Landesregierung, Abteilung Wasserwirtschaft, Josef-Huter-Straße 35, 6901 \\ Bregenz, Austria
}

\begin{abstract}
The river Lutz as many other rivers in Austria was forced into a straight and narrow river bed. Several weirs were erected to stabilise the river bed, but which, too, impeded organism passability. After decades with several floods the protection measures were in bad condition. In 2005, a 500-years flood caused heavy damage along the river and destroyed a main railway line. This incident initiated comprehensive planning activities to improve both, the flood protection as well as the ecological status of the river. Several technical measures focussing on stabilising the river bed, increasing the discharge capacity and improving the ecological status such as a step-pool-ramp with variable width, an open rip-rap, an increased river width as well as embankment groynes as an ecological and dynamic bank protection instead of a bank reinforcement were proposed. These measures were tested for feasibility and optimized in a physical model experiment.
\end{abstract}

\section{Introduction}

According to the requirements of flood protection during the beginning $20^{\text {th }}$ century, many rivers in Austria were forced into a straight and narrow river bed. So was the river Lutz in Vorarlberg/Austria. Concrete structures as steep bank reinforcements and several weirs with heights ranging from 0.5 to $2.5 \mathrm{~m}$ were erected to stabilise the river bed (see Fig. 1), but which, too, impeded organism passability. After decades with several floods the protection measures were in a bad condition. In 2005, finally a 500-years flood caused heavy damage along the river and destroyed a main railway line. This incident initiated comprehensive planning activities to improve both, the flood protection as well as the ecological status of the river.

* Corresponding author: ursula.stephan@baw.at 

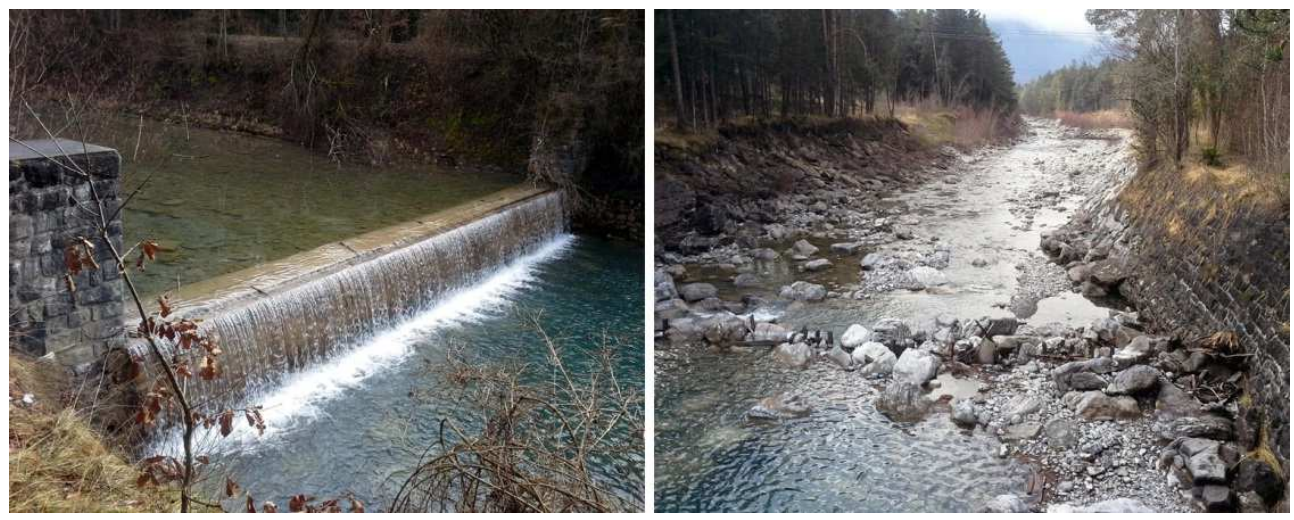

Fig. 1. An old weir (left) and steep and reinforced river banks (right) at the river Lutz

The concerned river section is $1600 \mathrm{~m}$ long and situated between Ludesch and Thüringen. It shows more or less a straight channel morphology with two bridges crossing the river. Several measures focussing on stabilising the river bed, increasing the discharge capacity and improving the ecological status were proposed (see Fig. 2):

- a step-pool-ramp sloped $4 \%$ with a variable width including a low-flow-channel and a downstream scour protection,

- $\quad$ an open rip-rap (revetment) sloped $1.3 \%$ including a low-flow-channel and large boulders as additional structure elements,

- $\quad$ an increased river width by $45 \%$ and embankments sloped 1:3 instead of $1: 1.3$ to increase the discharge capacity,

- embankment groynes as an ecological and dynamic bank protection instead of a bank reinforcement.

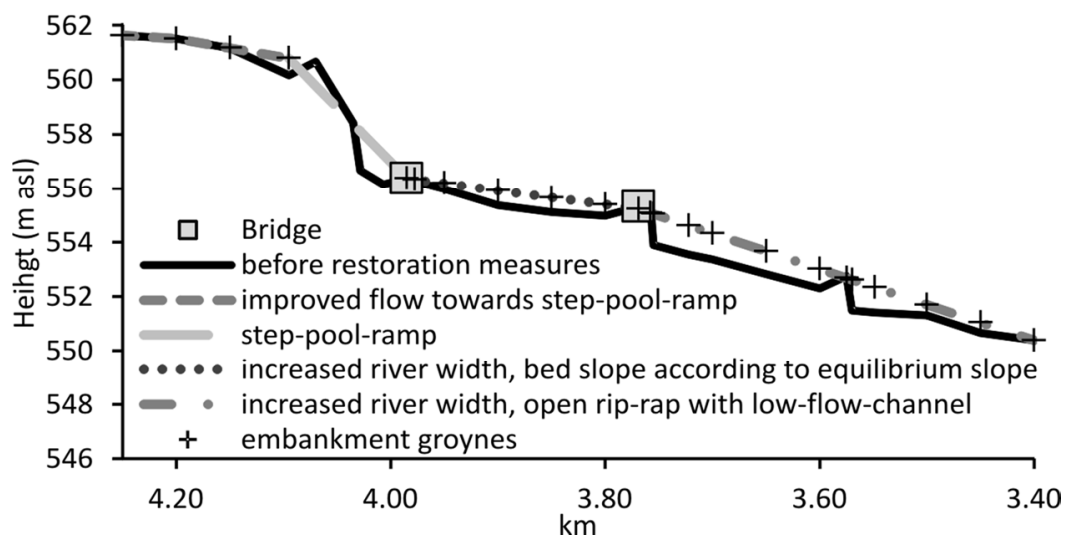

Fig. 2. Longitudinal profile of the concerned river reach with former and planned mean bed levels and the proposed restoration measures

The proposed measures were to be tested for feasibility and optimised in a physical model, on the one hand, to reliably protect the infrastructure as well as adjacent settlement areas against floods and, on the other hand, to optimise the material requirements of the proposed measures. 


\section{Flood protection and rehabilitation measures and main goals}

The length of the concerned river reach and its heterogeneity required a combination of different flood protection and rehabilitation measures to ensure both, an improved flood control and ecological status.

\subsection{Step-pool-ramp}

Step-pool-ramps are river restoration measures used to replace e.g. sills or weirs. In contrast to sills and weirs, step-pool-ramps guarantee a morphological continuity of the river bed and re-establish the biotic river continuum provided that the ramp slope is adapted to the swimming performance of the local fish community which in the present case corresponds to the Epirhithral (range of critical swimming velocity $1.5-3 \mathrm{~m} / \mathrm{s}$ ). Thus, the slope of the step-pool-ramp was fixed to $4 \%$ with a maximum step height of $25 \mathrm{~cm}$. The boulder size for steps and pools of the ramp were calculated according to [1] modified by [2], [3, 4, 5] as well as [6] taking the most reasonable, but smallest value in order to economically optimise the boulder size of the step-pool-ramp. Due to the narrowing river width of the step-poolramp in downstream direction from 30 to $20 \mathrm{~m}$ at the ramp toe under the bridge the experiments too focussed on the stability of the ramp toe as well as the adjacent scour protection.

\subsection{Open rip-rap}

An open rip-rap is a stone cover on the river bed made of armour stones with a low cover density leaving a considerable area of the original river bed uncovered by stones. This measure originally was developed for app. $0.2 \%$ sloped rivers [7]. The bed cover increases the flow resistance and, thus, reduces both the near-bed flow velocity as well as the erosion of the original bed material. Thus, an open rip-rap is a feasible bed stabilisation measure for river sections sloped higher than the equilibrium slope [8] and, thus, being in a state of erosion. [9] and [10] showed that this stabilisation measure can also be adapted to higher slopes than $0.2 \%$ and applied the method to a $1.3 \%$ sloped river section which closely corresponded to the current situation. The dimensioning of the armour stones was based on the incipient motion calculated according to [1] modified by [2] using $\theta_{\text {crit }}=0.025$ since the bed cover should be stable up to a HQ300. Thus, the size class III (300-800 kg) was chosen for the bed cover. The cover density was varied between 30 and $40 \%$ which meets both, ecological and morphological demands. Both, stone size and cover density were optimized within the scope of the experiments.

\subsection{Embankment groynes}

Embankment groynes used instead of a longitudinal bank reinforcement were another rehabilitation measure (see Fig. 3). On the area between the embankment groynes (groyne field) no additional stone cover was planned, on the one hand, to reduce the amount of stones needed as a bank protection and, on the other hand, to better support the growth of vegetation. The experiments mainly focussed on the extent of erosion of bank material within the groyne fields. As a result of the investigations, the groyne field length and the design of the groynes were expected to represent a minimum of both, amount of needed groyne stones and groyne field erosion for the straight part of the modelled river section as well as the slightly curved section. 


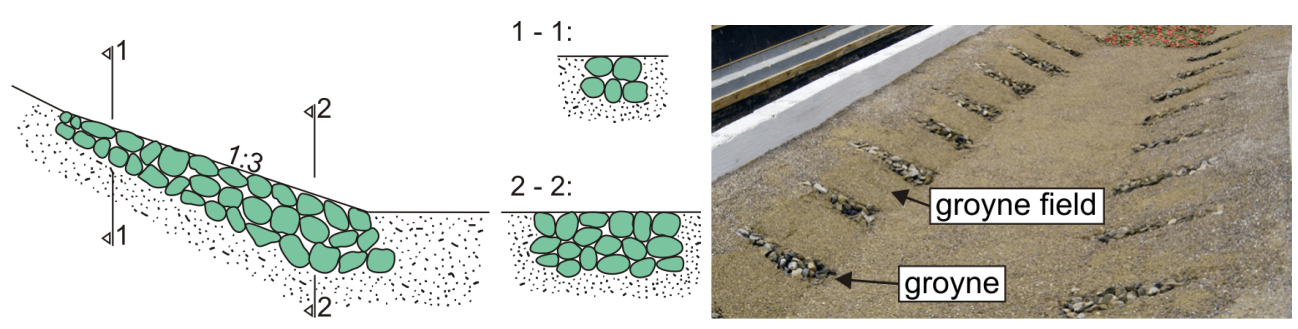

Fig. 3. Schematic sketch of embankment groynes (left) and implementation in the physical model (right)

\subsection{Low-flow-channel}

The modelled river section is situated downstream of a hydro power plant. Thus, the water flow in the channel is heavily influenced by the power plant operation. A very low residual flow of about $1 \mathrm{~m}^{3} / \mathrm{s}\left(\hat{=} 0.04 \mathrm{~m}^{3} / \mathrm{s} \cdot \mathrm{m}\right)$ downstream of the hydro power plant is to be expected throughout most of the year which is much less than the natural mean discharge of $12 \mathrm{~m}^{3} / \mathrm{s}$. In addition, due to the high permeability of the river bed the bed regularly dries out over long periods. For this reason, the formation of a stable low-flow-channel is of high importance for the biotic river continuum. In contrast to low flow periods high sediment transport is to be expected during high floods. Thus, the experiments also focussed on the stability and sustainability of the planned low-flow-channel (see Fig. 4) in case of sediment transport.

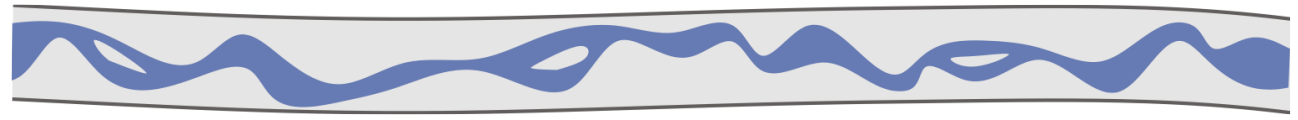

Fig. 4. Originally planned low-flow-channel

\section{Physical Model}

The modelled river section had a length of $1600 \mathrm{~m}$ and a width ranging from 20 to $30 \mathrm{~m}$ in nature. According to the available space of the laboratory flume the scale factor of the physical model was fixed at 1:30. The physical model was built with movable river bed and river banks. The sieve curve was geometrically scaled down from a mean natural sieve curve found at the Lutz. Grain sizes smaller than $0.2 \mathrm{~mm}$ (model scale size) were eliminated from the sieve curve since these grains are moved as suspended load without any effect on the morphology of the river bed. Thus, the characteristic grain sizes were $d_{m} /$ $\mathrm{d}_{30} / \mathrm{d}_{90}=58.1 / 12.7 / 146.9 \mathrm{~mm}$ (nature size). Due to a hydropower plant $2 \mathrm{~km}$ upstream of the modelled river section a considerable amount of sediment input into the concerned river section was not to be expected during low and mean flow periods. In addition, a small amount of sediment transport represents the less favourable variant in terms of bed and bank stability. Thus, the experiments were conducted without any sediment input into the river section.

Both, the gauge of Garsella and the overflow of the reservoir Gstins were used to derive the representative discharges (MNQ / HQ1/ HQ5 / HQ30 / HQ100 / HQ 300 / HQ500 = 1 / $30 / 110 / 205 / 220 / 250 / 276 \mathrm{~m}^{3} / \mathrm{s}$ ) and to define a model hydrograph for the concerned river section.

The main goals of the physical model (see Fig. 5) were to test the proposed construction types for feasibility, observe the failure mechanism in case of extreme floods, optimise boulder sizes and quantities, optimise the groyne geometry and interval to minimise the 
bank erosion and to observe the behaviour especially of the low-flow-channel in case of sediment transport.

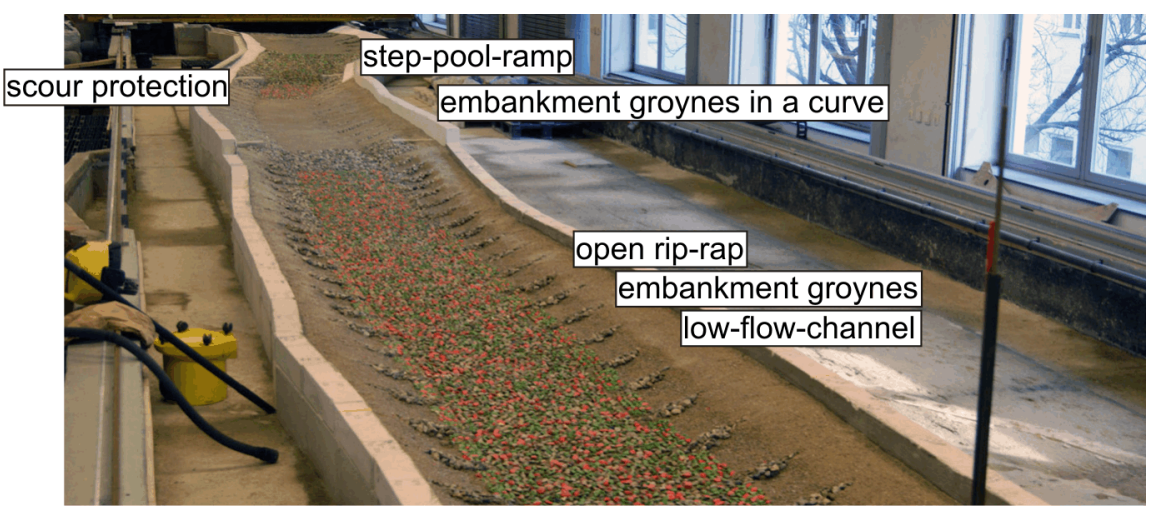

Fig. 5. Physical model - upstream view

\section{Results}

13 experimental series lead to a significantly changed design of the proposed measures compared to the original planning.

\section{Step-pool-ramp and downstream scour protection}

In the course of the experiments the stone size of the pool stones could be reduced by one size class from IV $(800-1500 \mathrm{~kg})$ to III $(300-800 \mathrm{~kg})$ due to an oversized ramp stability even during extreme floods. On the banks, the bars were constructed analogously to the bars on the ramp, but the experiments showed that no additional stone cover between the bars was needed.

Special attention was given to the stability of the ramp toe, since the ramp toe was situated right under a bridge. Compared to the original version, the lowest bar of the ramp was made of slightly larger stones (size class VI, 2000-3000 kg) than the other bars (size class V-VI, 1500-3000 kg) to prevent any bar failure during an extreme flood event. The optimised length of the scour protection was shortened to only a forth of the original length (see Fig. 6) and the cover density, too, was reduced significantly from 70 to $30 \%$. 1/6 of the river width on both sides remained densely covered by stones.

Due to the reduced cover density in the center of the cross section, the river bed could self-actingly adapt to the flow by forming a scour for energy dissipation dependent on the hydrology. The densely covered edge strips were arranged to protect the bridge foundation in particular and to serve as a stone depot to enable cover stones being shifted from the side into the scour hole if needed, e.g. due to a high scour depth subsequently to an extreme flood event. Thus, the scour hole was free to develop but limited in its depth.

$$
\text { के }
$$

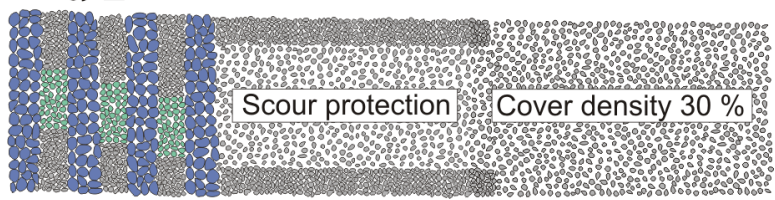

Dense stone cover

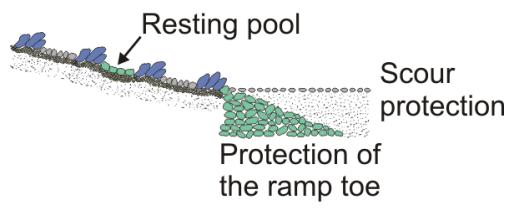

Fig. 6. Plan view and longitudinal profile of the step-pool-ramp and scour protection 
To improve the upstream migration of fish and other aquatic organism additional resting pools within the ramp pools were arranged providing an $80 \%$ higher depth than the adjacent pool areas. These resting pools were sized approximately $20 \%$ of the area of each ramp pool and covered with larger stones in order to not being eroded in case of high discharges due to locally increased shear stresses.

\section{Embankment groynes}

Embankment groynes were situated in the 0.5 and $1.3 \%$ sloped river section, the former in a slightly curved section without any bed protection measures since the slope approximately corresponded to the equilibrium slope of the river, the latter in a straight section covered with an open rip-rap. The ratio river width to groyne field length ranged between 1.5 and 1.9. In the curved section, the experiments showed a critical amount of bank erosion especially on the outer bank. The heads of the groynes were endangered to be eroded due to the scour developing in the outer curve and this, subsequently, resulted in high erosion rates on the banks and a partial destruction of the groynes (see Fig. 7). As a solution, four longitudinal rows of stones embedded in the river bed along the groyne heads remarkably reduced the amount of bank erosion due to an increased stability of the groynes and reduced secondary currents and turbulences within the groyne fields. Along the inner bank of the curve no alignments were needed.
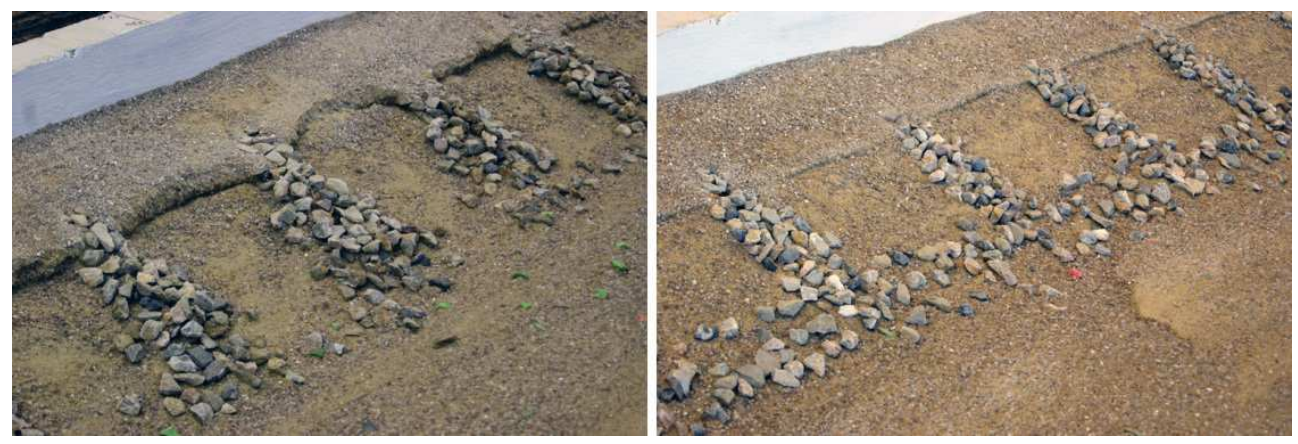

Fig. 7. Original design of the embankment groynes without alignments (left) and optimised version (right) after a HQ100

These longitudinal rows of stones along the groyne heads were also implemented in the $1.3 \%$ sloped river section stabilised by the open rip-rap for not endangering the bed cover due to critical bank erosion rates.

\section{Open rip-rap and low-flow-channel}

The $1.3 \%$ sloped river section originally was planned to be stabilised by ground sills made of stones. This approach resulted in a highly turbulent and wavy flow field due to bed erosion between the ground sills which, too, led to high erosions rates on the banks. In contrast to a river section with ground sills, an open rip-rap exhibits a more homogeneous bed surface and, thus, a substantially reduced wave formation. Therefore, an open rip-rap was preferred to a bed stabilisation by ground sills in order to avoid high bank erosion rates. In the course of the experiments, additional adaptions concerning the stone size and the cover density ensuring a balanced ratio between the cost-minimising amount of cover stones and the needed river bed protection were conducted.

The original design of the low-flow-channel (see Fig. 4) turned out not to be sustainable in case of high flood events and, thus, high sediment transport rates since the channel was completely filled with sediment after an extreme flood event. Therefore, the curved and 
almost braided geometry of the low-flow-channel had to be turned into a straight geometry with a width of $6 \mathrm{~m}$ and a depth of $0.40 \mathrm{~m}$ concentrating the flow in the middle of the cross section to prevent sediment deposition in case of sediment transport. As a supplement to this rather monotonous geometry several groups of boulders (1500-3000 kg) were arranged alongside the low-flow-channel to ecologically structure the flow as well as locally reduce the flow velocity. Subsequently, sideways of the baffles elongated scours were formed by the flow in case of high discharges due to a slight erosion of the subsurface material, but not endangering the surface stone cover.

Implementing these changes the proposed bed stabilisation and the ecological measures proved to be suitable over the whole range of discharges up to the design flood (HQ300 $\hat{=}$ $250 \mathrm{~m}^{3} / \mathrm{s}$ ) and exhibited an improved flood protection even for an extreme flood event such as a HQ500 (Fig. 8).

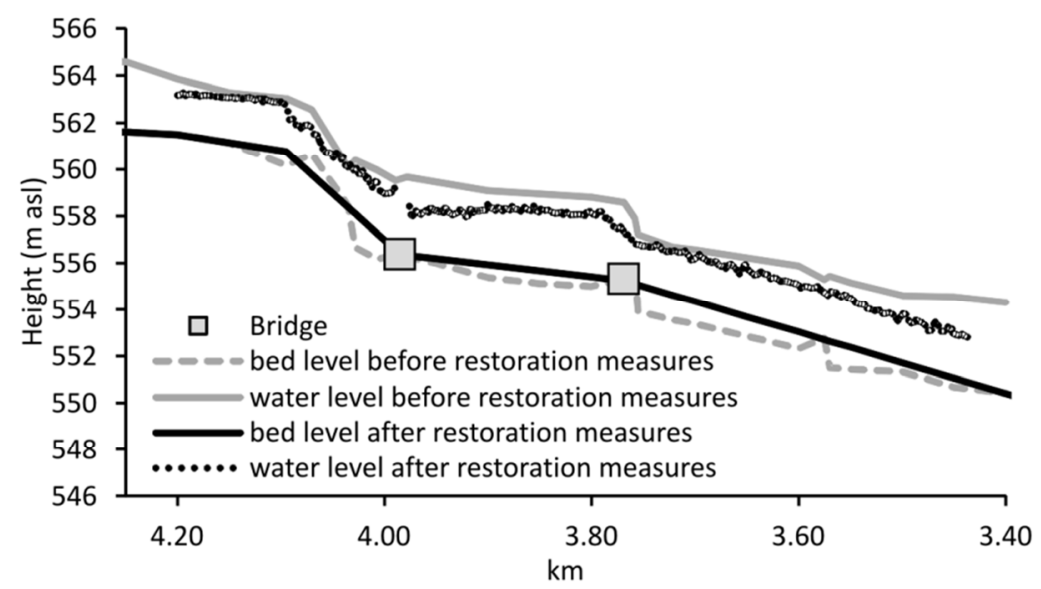

Fig. 8. Longitudinal profile of the concerned river reach with water (HQ500) and bed levels before and after the restoration measures

Overloading by an extreme flood event (HQ500) caused merely minor and local damage such as a slight mobilization of the open rip-rap and slowly progressing depth erosion.

\section{Implementation of the measures}

All measures were successfully implemented in winter 2015/16 (Fig. 9) and led to costsavings due to reduced stone sizes and cover densities which exceeded the model costs by 6-times.
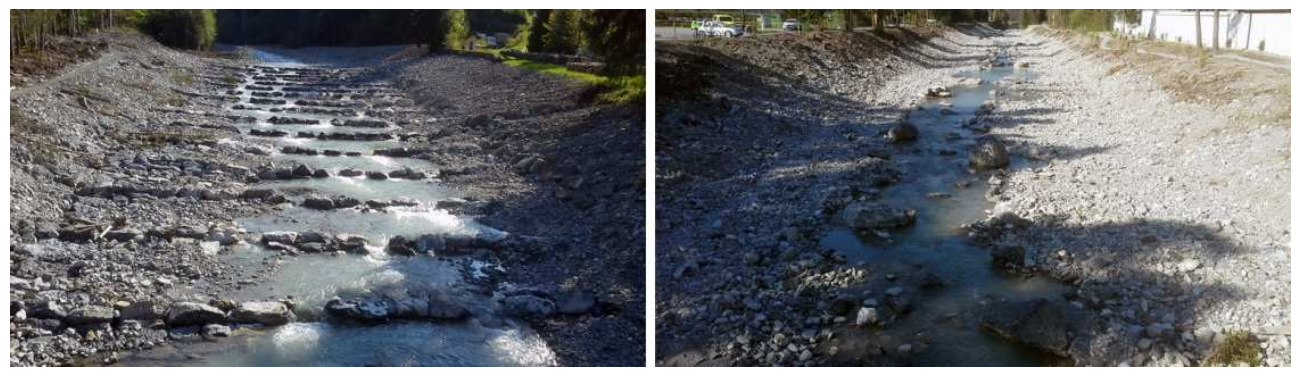

Fig. 9. Step-pool-ramp (left) and open rip-rap with low-water-channel and structuring boulders after implementation of all measures (2016) (discharge appr. $1 \mathrm{~m}^{3} / \mathrm{s}$ ) 


\section{Conclusion}

Different ecological and economical flood protection measures to sustainably stabilize a river stretch endangered by bed erosion were investigated in a physical model. Several experimental series lead to a significantly changed design of the proposed measures compared to the original planning. The main changes concerned

- the optimisation of stone and boulder sizes of the step-pool-ramp including the downstream scour protection, the open rip-rap and the embankment groynes,

- an optimised cover density of the open rip-rap ensuring a balanced ratio between the cost-minimising amount of cover stones and the needed river bed protection,

- the design of the embankment groynes and

- the design of the proposed curved geometry of the low-flow-channel which was turned into a straight one concentrating the flow in the middle of the cross section to prevent sediment deposition in case of sediment transport.

Boulder sizes as well as material requirement could significantly be reduced. The proposed design of the embankment groynes led to a certain but acceptable amount of bank erosion in the straight river section, but had to be adapted in the bend due to the scour development near the head of the groynes. The organism passability also in case of very low flow situations could be guaranteed due to the re-designed low-flow-channel.

\section{References}

1. E. Meyer-Peter, R. Mueller. 1948. Formulas for Bed-Load Transport. IAHSR. Report on the Second Meeting, Stockholm. June 7-9 (1948)

2. R. Hunziker, Mitteilung der Versuchsanstalt für Wasserbau, Hydrologie und Glaziologie der ETH Zürich, 138 (1995)

3. S. Pagliara, P. Chiavaccini, Journal of Hydraulic Engineering, ASCE, 132, No.6, 545552 (2006)

4. LUBW, Durchgängigkeit für Tiere in Fließgewässern - Umgehungsgewässer und fischpassierbare Querbauwerke, 101 (2006)

5. N. Korecky, Proc. of the $32^{\text {nd }}$ Congress of IAHR, Harmonizing the Demands of Art and Nature in Hydraulics, Venice, Italy, 611 (2007)

6. N. Korecky, M. Hengl, Wasserwirtschaft, 1-2 (2008)

7. A. Hartlieb, Berichte des Lehrstuhls und der Versuchsanstalt für Wasserbau und Wasserwirtschaft der Technischen Universität München, 85 (1999)

8. M. Hengl, U. Stephan, Österr. Wasser- und Abfallwirtschaft 60, Heft 11-12, 193-199 (2008)

9. M. Hengl, M. Längle, Proceedings of the $2^{\text {nd }}$ IAHR Europe Conference, B20 (2012)

10. U. Stephan, M. Hengl, M. Manser, Proc. of the Int. Conf. on Fluv. Hydraulics (River Flow 2014), 2135-2143 (2014)

11. Werner Consult, Gefahrenzonenplanung Lutz (2008) 